\title{
Spore dispersal, diurnal pattern and viability of Monilinia spp. conidia and the relationship with weather components in an organic apple orchard
}

\author{
Abonyi, F., Vámos, A., Rózsa, A., Lakatos P. \& Holb, I.J. \\ University of Debrecen, P.O. Box 36, H-4015 Debrecen, Hungary (e-mail: holb@agr.unideb.hu)
}

\begin{abstract}
Summary: In a two-year Hungarian study, spore dispersal diurnal periodicity and viability of Monilinia spp. and their relation to weather components were determined in an organic apple orchard. Conidia of Monilinia spp. were first trapped in late May in both years. Low number of conidia were trapped until end-June. Thereafter, number of conidia continuously increased until harvest. Conidia in a 24-h period showed diurnal periodicity pattern, with th highest concentration in the afternoon hours. Spore viability with FDA staining showed that viability of conidia ranged from 45 to $70 \%$ with showing lower viability in the dry than in the wet days in both years. Temperature and relative humidity correlated positively with mean hourly conidia numbers in both years. Mean hourly rainfall was negatively but poorly correlated with conidia catches in both years. Results were compared and discussed with previous observations.
\end{abstract}

Keywords: aerial dispersal, brown rot, epidemiology, viability, diurnal periodicity, organic, apple

\section{Introduction}

Monilinia spp is the causative genus of fruit rot in fruit crops in the temperate regions of the world (Byrde \& Willetts, 1977; Holb, 2006, 2008a). Dispersal of Monilinia spp. conidia can occur mainly by wind, water, insects, birds and man. Short range transport of conidia could be considered by splash dispersal (Byrde \& Willetts, 1977). Few studies monitored dispersal of $M$. fructigena conidia. Airborne conidia have been trapped on exposed dishes and vaseline slides (Horne, 1933). Water was shown to be an important factor for spreading conidia within the tree (Pauvert et al., 1969). Insect dispersal of conidia has also been an importamt factor from one fruit to another (Croxall et al., 1951; Lack, 1989). Studies demonstrated a low aerial concentration of M. fructigena in integrated apple orchards (Van Leeuwen et al., 2000; Xu et al., 2001; Holb, 2008b) while in organic apple orchards high conidial concentration were recorded (Holb, 2008b; Holb et al., 2011). Previous studies showed that viability of trapped conidia was $60 \%$ (Holb, 2008b). Relative humidity, mean temperature, and wind were shown to be important in explaining the variation in hourly spore counts of M. fructigena conidia (Holb, 2008b; Bannon et al., 2009).

The aims of this two-year study were to i) monitor conidial content of Monilinia spp. in the air from mid-May until harvest; ii) determine diurnal periodicity of trapped conidia iii) evaluate viability of trapped spores; and iv) correlate spore data with weather variables of relative hunidamidity, temperature and rainfall in an organic apple orchard.

\section{Materials and methods}

\section{Orchard sites}

A two-year study (2013 and 2014) was done in an organic apple orchard in eastern Hungary. The orchard, located in Eperjeske consisted of eight apple cultivars, with a distance between rows of $5 \mathrm{~m}$ and within a row of $2 \mathrm{~m}$. Orchard soil type was brown forest soil and Hungarian organic production guidelines have been applied since the planting of the orchard. Trees were planted in 1996 on M26 rootstock and were pruned to spindle shape. All sprays were applied with a Kertitox 2000 axial blower spray machine.

\section{Monitoring environmental variables}

Temperature $\left({ }^{\circ} \mathrm{C}\right)$, relative humidity $(\%)$, and rainfall $(\mathrm{mm})$ were detected with a Metos Compact agrometeorological station from 20 May until 10 October in 2013 and 2014. Detecting sensors were mounted $1 \mathrm{~m}$ above the ground in the centre of the canopy of a tree during.

\section{Quantifying airborne conidia}

Conidia was monitored with a Burkard 7-day recording volumetric spore trap which was placed in the centre of an orchard. The spore trap were placed about $1.5 \mathrm{~m}$ above ground level (Kable, 1965; Corbin et al., 1968; Leeuwen et al., 2000; Holb, 2008). Spore traps were operated from 20 May until mid-October in both years. Spore trap was operated at a flow 
rate of $10 \mathrm{~L} \mathrm{~min}^{-1}$. (Willocquet \& Clerjeau, 1998; Holb et al., 2004). The tapes of spore traps were cut into seven $48-\mathrm{mm}$ long sections. Each piece of tape was examined and conidia was counted with a microscope. Only limoniform-shaped conidia were identified as Monilinia spp. van Leeuwen et al. (2002). Hourly spore counts were also made.

\section{Spore viability test}

30 days spore trap data were used for determining the viability of trapped conidia. Strips were submerged in a 1:10 solution of fluorescein diacetate. After incubation for $20 \mathrm{~min}$ strips were mounted in gelvatol. The stripds were examined for living and dead $M$. fructigena conidia. Viable conidia stained bright yellow with FDA under a Zeiss Jenamed fluorescence microscope.

\section{Data analyses}

Conidial dispersal was examined by plotting daily totals of spore caught. Diurnal periodicity was evaluated by plotting the mean proportion of spores caught each hour $(24.00$ to 24.00 hour) during the 30 -day period. Days for viability test were sorted into two classification categories: i) dry, with less precipitation than $1 \mathrm{~mm} \mathrm{day}^{-1}$ and iii) wet, with larger precipitation than $5 \mathrm{~mm}^{\text {day }}{ }^{-1}$. LSD tests $(\mathrm{P}=0.05)$ were applied to compare percent viability values estimated for the two categories. Relationship among environmental variables and conidia numbers were analysed by calculating Pearson correlation coefficients and associated significance levels.

\section{Results}

\section{Seasonal conidial concentration}

Seasonal concentrations of conidia increased with brown rot incidence. Decrease in the numbers of conidia was detected when weather was rainy longer than four subsequent days. Conidia of Monilinia spp. were first trapped in late May. Conidia were trapped with a relatively low numbers but continuously between end-May and end-June. From end-June numbers of conidia continuously increased until harvest.

\section{Diurnal periodicity of airborne conidia}

The pattern of mean hourly proportions of conidia caught over a 24-h period showed diurnal periodicity (Fig. 1). Most spores were caught between 10.00 and 19.00 hours. Peak aerial conidia concentration occurred in the afternoon. Maximum spore catch occurred at 16.00 and 17.00 hour.

\section{Viability of conidia}

Viability of Monilinia spp. conidia ranged from 45.2 to $70.1 \%$ from early September until harvest over the two years (Table 1). Spore viability was lowest in the dry and the highest in the wet days and spore viability was significant at $\mathrm{P}<$ 0.05 between dry and wet days for both years.

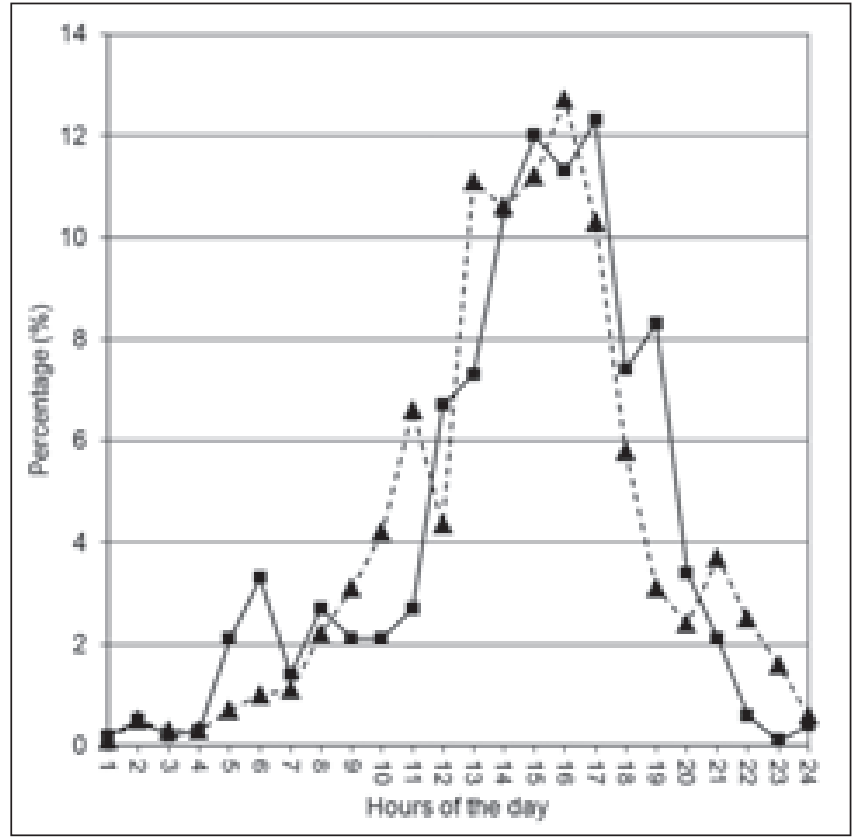

Figure 1. Patterns of diurnal periodicity of Monilinia spp. (Eperjeske, Hungary, 2013 and 2014)

Table 1. Percent viability of Monilinia spp. conidia in dry and wet days sampled from mid-September until harvest an organic apple orchard (Eperjeske, Hungary, 2013-2014)

\begin{tabular}{|c|c|c|c|}
\hline Year & Dry & Wet & F-test $^{\text {a }}$ \\
\hline 2013 & $45.2 \mathrm{a}$ & $61.8 \mathrm{~b}$ & $*$ \\
\hline 2014 & $53.8 \mathrm{a}$ & $70.1 \mathrm{~b}$ & $*$ \\
\hline
\end{tabular}

${ }^{a}$ Values within rows followed by different letters are significantly different. LSD t-test was used for comparing sampled periods; * is significantly different at 0.05 , respectively.

Correlation between conidial content and environmental variables

Temperature and relative humidity correlated positively with mean hourly conidia numbers in both years (Table 2). Mean hourly rainfall was negatively but poorly correlated with conidia catches in both years.

Table 2. Correlation coefficients $(r)$ between mean hourly concentration of Monilinia spp conidia and temperature, relative humidity and rain in an organic apple orchard from 20 May until mid-October (Eperjeske, Hungary, 2013-2014)

\begin{tabular}{|c|c|c|c|}
\hline Site and year & Temperature & Relative humidity & Rain \\
\hline 2013 & $0.31 *$ & $0.25 *$ & $-0.13 \mathrm{~ns}$ \\
\hline 2014 & $0.36 * *$ & $0.36 * *$ & $-0.08 \mathrm{~ns}$ \\
\hline
\end{tabular}

a correlation coefficient.

${ }^{\mathrm{b}} \mathrm{ns},{ }^{*}$ and $* *$ are significantly different at nonsignificant, 0.05 and 0.01 , respectively.

\section{Discussion}

Aerial spore contents of Monilinia spp. were demonstrated in an organic apple orchards. Diurnal pattern and high 
viability percentage of trapped conidia were shown. Strong relationship was found among hourly spore counts and low relative humidity and high temperature.

Mean daily conidia started to continuously increase only when first infected and sporulating fruits in this study. Similarly to results of this study a previous Dutch and Hungarian studies (Van Leeuwen et al., 2000; Holb, 2008b) demonstrated that dispersal of $M$. fructigena conidia increased after the appearence of first infected fruits. During the whole trapped periods, conidia were significantly in this study (organic orchard) compared with other studies in integrated orchard (van Leeuwen et al., 2000; Xu et al., 2001; .Holb, 2008b). A previous study from the on M. fructicola (Corbin et al., 1968) demonstrated that conidia dispersal period occured between blossom and the appearance of first fruit. $M$. fructigena does not cause blossom and/or twig blight in apple in the Central-European region (Holb et al., 2004); therefore, conidial inoculum is originated from other sources. Spring conidia can be originated from sporulating mummified fruits that overwintered in the tree canopy (Van Leeuwen et al., 2002) and summer inoculum from the dopped fruit on the orchard floor (Holb \& Scherm, 2007).

Viability of trapped conidia was the highest when it was collected under wet conditions with the lowest temperatures (Table 1). In the study of van Leeuwen (2000), 60\% viability was similar to our results. Results also agreed with previous laboratory studies (Naqvi \& Good, 1957; Xu et al., 2001) as higher temperatures resulted in a reduction in conidial viability. Relationship between weather variables and viability data from field sampled spores are quite difficult to interpret as weather variables are fluctuating under field conditions.

A diurnal fluctuation in conidia concentration was observed, which approached similar type that was reported by Hirst (1953). Similarly to this study, previous studies (Kable, 1965; Jenkins, 1965; Corbin et al., 1968; Holb, 2008b) on Monilinia spp. also demonstrated a significantly higher conidia in the afternoon and evening hours. The highest temperature mostly occurs from the early afternoon hours until late afternoon hours. As most spores also trapped during this period the positive association are also justified by Pearson correlation as there were strong positive correlations between hourly spore content and temperature.

\section{Acknowledgements}

This research was supported partly by a grant of the Hungarian Scientific Research Fund (OTKA K108333).

\section{References}

Bannon, F., Gort, G., van Leeuwen G. C. M., Holb, I.J., \& Jeger, M. (2009): Diurnal patterns in dispersal of Monilinia fructigena conidia in an apple orchard in relation to weather factors. Agricultural and Forest Meteorology, 149 (3): 518-525.

Byrde, R. J. W., \& Willetts, H. J. (1977): The brown rot fungi of fruit: their biology and control. Oxford, UK: Pergamon Press.
Corbin, J. B., Ogawa, J. M., \& Schultz, H. B. (1968): Fluctuations in numbers of Monilinia laxa conidia in an apricot orchard during the 1966 season. Phytopathology, 58: 1387-1394.

Croxall, H. E., Collingwood, C. A., \& Jenkins, J. E. E. (1951): Observations on brown rot (Sclerotinia fructigena) of apples in relation to injury caused by earwigs (Forficula auricularia). Annals of Applied Biology, 38: 833-843.

Hirst, J. M. (1953): Changes in atmospheric spore content: diurnal periodicity and the effects of weather. Transactions of the British Mycological Society, 36: 375-393.

Holb IJ (2006): Possibilities of brown rot management in organic stone fruit production in Hungary. International Journal Of Horticultural Science, 12 (3): 87-92.

Holb IJ (2008a): Brown rot blossom blight of pome and stone fruits: symptom, disease cycle, host resistance, and biological control. International Journal Of Horticultural Science, 14 (3): 15-21.

Holb IJ (2008b): Monitoring conidial density of Monilinia fructigena in the air in relation to brown rot development in integrated and organic apple orchards. European Journal of Plant Pathology, 120 (4): 397-408.

Holb, I. J., Heijne, B., Withagen, J. C. M., \& Jeger, M. J. (2004): Spread of Venturia inaequalis from a defined source of ascospores into a disease-eradicated orchard section. Journal of Phytopathology, 152: 639-646.

Holb, I. J., \& Scherm, H. (2007): Temporal dynamics of brown rot in different apple management systems and importance of dropped fruit for disease development. Phytopathology, 97: 1004-1111.

Holb I J, Balla B, Abonyi F, Fazekas M, Lakatos P, Gall J M (2011) Development and evaluation of a model for management of brown rot in organic apple orchards. European Journal of Plant Pathology, 129: 469-483.

Horne, A. S. (1933): Biological work on fruit. Report of the Food Investigation Board 1932, London, UK 279-300.

Jenkins, P. T. (1965): The dispersal of conidia of Sclerotinia fructicola (Wint.) Rehm. Australian Journal of Agricultural Research, 16: 627-633.

Kable, P. F. (1965): Air dispersal of conidia of Monilinia fructicola in peach orchards. Australian Journal of Experimental Agriculture and Animal Husbandry, 5: 166-171.

Lack, H. (1989): The spread of apple brown rot (Monilinia fructigena) by insects. Annals of Applied Biology, 115: 221-227.

Naqvi, S.H.Z., \& Good, H.M. (1957) Studies of the aging of conidia of Monilinia fructicola (Wint.) Honey. I. Germination rates and longevity. Canadian Journal of Botany, 35: 635-45.

Pauvert, P., Fournet, J., \& Rapilly, F. (1969): Études sur la dispersion d'un inoculum par des gouttes d'eau en fonction du conceptacle sporifère. Annales de Phytopatologie, 1: 491-493.

Van Leeuwen, G. C. M., Holb, I. J., \& Jeger, M. J. (2002): Factors affecting mummification and sporulation of pome fruit infected by Monilia fructigena in Dutch orchards. Plant Pathology, 51: 787-793.

Van Leeuwen, G. C. M., Stein, A., Holb, I. J., \& Jeger, M. J. (2000): Yield loss in apple caused by Monilinia fructigena (Aderh. \& Ruhl.) Honey, and spatio-temporal dynamics of disease development. European Journal of Plant Pathology, 106: 519-528.

Van Leeuwen, G. C. M. (2000): The brown rot fungi of fruit crops (Monilinia spp.), with special reference to Monilinia fructigena (Aderh. \& Ruhl.) Honey. PhD thesis. Wageningen University, Wageningen, The Netherlands. 113 pp.

Willocquet L, \& Clerjeau M. (1998): An analysis of the effects of environmental factors on conidial dispersal of Uncinula necator (grape powdery mildew) in vineyards. Plant Pathology, 47, 227-33. Xu, X.-M., Guerin, L., \& Robinson, J. D. (2001): Effects of temperature and relative humidity on conidial germination and viability, colonization and sporulation of Monilinia fructigena. Plant Pathology, 50: 561-568. 